\title{
Differences of Driving Experience and Gender on Traffic Offences Among Malaysian Motorists
}

\author{
Sharifah Liew ${ }^{1, *}$, Rizati Hamidun ${ }^{1}$, and Nor Fadilah Mohd Soid ${ }^{1}$ \\ ${ }^{1}$ Malaysian Institute of Road Safety Research, Kajang, Malaysia
}

\begin{abstract}
This study attempt to examine the influence of driving experience and gender on different traffic offences. Questionnaire survey was conducted to measure the frequency of committing eleven types of traffic. Data collected were analysed using t-test and Chi-square. Results indicate that male drivers have high score in speeding, red light running, tailgating and using emergency lane. Significant differences emerged between driving experiences in speeding, red light running, dangerously cutting into traffic, using hand phone while driving/riding and driving/riding with noncompliance specification vehicle.
\end{abstract}

\section{Introduction}

Road accidents is known as a concern to public health, resulted about 1.2 million deaths worldwide [1]. Proposing traffic regulation is one of the countermeasure taken aimed to reduce the frequency and severity of road accident. Ignore to the traffic regulation is among the human behavioural factor that may lead to the road accident [2].

Traffic offences such as speeding, red light running, tailgating and using emergency would trouble other road users and might end up with an accident. Speeding would contribute to more severe accident due to high impact [3], yet difficult to handle since it is a widespread phenomenon [4]. The offence of speeding have found to be associated with driver impulsivity [5]. Traffic offences somehow related to the expression of driving anger [6].

Relationship of traffic offences and driving experience had been studied by previous researcher. For example, red light running violation through simulation experiment examined by $\mathrm{Wu}$ et al. [7] for taxi drivers and non-professional drivers. Results indicated that taxi drivers prone to violate traffic light as compared to the non-professional drivers. In other studies, effect of fog to driving performance for professional and non-professional drivers had been conducted by [8] using simulation experiment.

Although several studies have focus on the driving experience, study on the differences of driving experience on traffic offences is still limited. Thus, this study explores the differences of driving experience toward accident involvement, summon received and 10 types of traffic offences and gender.

\footnotetext{
* Corresponding author: sharifahliew@miros.gov.my
} 


\section{Methodology}

\subsection{Data collection}

This study was conducted using semi-quantitative approach and was carried out by using self-administered questionnaire to collect data on the road users' aberrant behaviour. The survey was conducted in north and south of PLUS expressway and selected area in Klang Valley. The target population for this study comprised of road users who own a valid driving license. Total of 300 respondents were involved in this study, 177 (59.8\%) respondents were motorist and $119(40.2 \%)$ respondents were motorcyclists. The respondents were randomly selected from two zone Klang Valley and expressway heading to north and south as shown in Table 1 below.

Table 1. Survey locations

\begin{tabular}{cc}
\hline Zone & Location \\
\hline \multirow{2}{*}{ Klang Valley } & Tesco Klang \\
\cline { 2 - 2 } & Tesco Ampang \\
\hline \multirow{2}{*}{$\begin{array}{c}\text { Expressway heading to } \\
\text { north and south }\end{array}$} & Genting Sempah \\
\cline { 2 - 2 } & RnR Rawang \\
\hline
\end{tabular}

\subsubsection{Respondents}

A total of 300 respondents participated in the study, $56 \%$ of them are male and $44 \%$ of them females. The majority of the respondents came from the age group of 26 to 35 years old $(33.3 \%), 36$ to 45 years old $(20.7 \%) \&$ more than 46 years old $(25.7 \%)$; there were only $20.3 \%$ of respondents who were less than 25 years old. All respondents have driving licences with varies period in driving experiences. The majority of respondents has 3-10 years of driving experience. About $73.1 \%$ of the respondents were married. In terms of race, $71.6 \%$ were Malays, $13.9 \%$ Chinese and $14.5 \%$ Indian. More than half of the respondents had higher than tertiary education level. Among the respondents, $59.8 \%$ were car drivers while the rest were motorcyclists.

\subsubsection{Questionnaires}

The questionnaires for this study were designed to gather information related to the respondents' demographic characteristics, accident and summon experience and their involvement in the traffic offences. The questionnaire consisted of three parts. Part A contained the respondents' demographic information such as age, driving experience, education, race, religion; Part B asking about an involvement of respondent in an accident and summon received. Part $\mathrm{C}$ is about the frequency of committing different types offences by respondents. Offences measured are: (1) speeding; (2) red light running; (3) overtaking at double lines; (4) queue jumping; (5) illegal use of emergency lane using mobile phone while riding/driving; (6) dangerously cutting into traffic; (7) using hand phone while driving / riding; (8) not wearing seatbelt / helmet; (9) driving/riding with expired road tax; (10) driving/riding with noncompliance specification vehicle and (11) dangerously cutting 
into traffic. The frequency of committing the 11 traffic offences was measured using score from 0 (never) to 10 (most of the time).

\subsection{Data analysis}

Data collected has been coded and analysed using SPSS. Descriptive statistics such as mean and percentage was performed to describe the overall of aberrant behaviour and the perception towards traffic enforcement visibility. While inferential statistics such as the Chi-square, T-test and ANOVA was performed to achieve the objective of the research which were to examine the differences between aberrant behaviour and selected demographic factors.

\section{Results}

Table 2 shows the non-parametric correlation between the demographic variables and the accident involvement of the respondents. It shows that there is a significant relation between the gender and their accidents involvement.

Table 2. Non-parametric test for accident involvement and demographic details

\begin{tabular}{lcccc}
\hline Demographic Details & \multicolumn{2}{c}{ Accident Involvement } & Chi-Square & P-value \\
& Yes (n) & No (n) & & \\
\hline Gender & 69 & 99 & 12.262 & 0.000 \\
$\quad$ Male & 29 & 103 & & \\
$\quad$ Female & 5 & 23 & 4.667 & 0.198 \\
Driving Experience & 35 & 75 & & \\
$\quad$ Less than 2 & 35 & 54 & & \\
$3-10$ & 23 & 50 & & \\
$11-20$ & & & & \\
More than 20 & & & \\
\hline
\end{tabular}

Table 3 presents the non-parametric test between the demographic variables and the summon received by the respondents. It is found that there is a significant relation between gender and the summons received by the individuals.

Table 3. Non-parametric test for summon received and demographic details

\begin{tabular}{lcccc}
\hline Demographic Details & \multicolumn{2}{c}{ Summon Received } & Chi-Square & P-value \\
& Yes (n) & No (n) & & \\
\hline Gender & 78 & 87 & 14.110 & 0.000 \\
$\quad$ Male & 34 & 97 & & \\
$\quad$ Female & & & 7.374 & 0.061 \\
Driving Experience & 6 & 22 & & \\
$\quad$ Less than 2 & 41 & 69 & & \\
3-10 & 32 & 57 & & \\
11-20 & 36 & 37 & & \\
$\quad$ More than 20 & & & \\
\hline
\end{tabular}

Table 4 shows the means for both sex for the different measures of traffic offences studied. The t-values found are presented along with their statistical meaning. By comparison, the men showed higher score in speeding, red light running, illegal use of emergency lane and tailgating significantly. 
Table 4. Mean and sex comparisons of the measures of traffic offences

\begin{tabular}{lcccc}
\hline \multicolumn{1}{c}{ Traffic Offense } & $\begin{array}{c}\text { Male } \\
\text { (Mean) }\end{array}$ & $\begin{array}{c}\text { Female } \\
\text { (Mean) }\end{array}$ & t & p-value \\
\hline Speeding & 2.70 & 1.82 & 2.878 & $0.004^{*}$ \\
Red light running & 1.67 & 1.06 & 2.447 & $0.015^{*}$ \\
Overtaking at double line & 1.30 & 0.89 & 1.792 & 0.074 \\
Queue jumping & 1.41 & 1.34 & 0.267 & 0.790 \\
Illegal use of emergency lane & 1.33 & 0.86 & 1.965 & $0.050^{*}$ \\
Dangerously cutting into traffic & 1.88 & 1.47 & 1.403 & 0.162 \\
Not wearing seatbelt/helmet & 1.82 & 1.47 & 1.216 & 0.225 \\
Using hand phone while driving/riding & 1.43 & 1.25 & 0.765 & 0.228 \\
Tailgating & 1.39 & 0.77 & 2.930 & $0.004^{*}$ \\
Driving/riding with expired road tax & 0.67 & 0.54 & 0.698 & 0.486 \\
$\begin{array}{l}\text { Driving/riding with noncompliance } \\
\text { specification vehicle }\end{array}$ & 0.59 & 0.39 & 1.125 & 0.262 \\
\hline
\end{tabular}

Result on the comparison between driving experience and the traffic offences is indicated in Table 5. It is observed that experience has significant differences in the area of speeding, red light running, dangerously cutting into traffic, using hand phone while driving/riding and driving/riding with noncompliance specification vehicle.

Table 5. Comparisons between driving experience and the traffic offences

\begin{tabular}{lcc}
\hline \multicolumn{1}{c}{ Traffic Offense } & F & p-value \\
\hline Speeding & 2.952 & $0.033^{*}$ \\
Red light running & 3.471 & $0.017^{*}$ \\
Overtaking at double line & 0.945 & 0.419 \\
Queue jumping & 0.193 & 0.901 \\
Illegal use of emergency lane & 0.746 & 0.525 \\
Dangerously cutting into traffic & 4.874 & $0.003^{*}$ \\
Not wearing seatbelt / helmet & 2.118 & 0.098 \\
Using hand phone while driving / riding & 3.299 & $0.021^{*}$ \\
Tailgating & 0.549 & 0.649 \\
Driving/riding with expired road tax & 2.065 & 0.105 \\
Driving/riding with noncompliance specification & & \\
vehicle & 2.803 & $0.040^{*}$ \\
\hline
\end{tabular}

\section{Discussions and conclusion}

The purpose of the study was to explore the differences of driving experience and gender in accident involvement, summon received and involvement in traffic offences. Analysis showed gender differences in accident involvement, experience of being summonsed and several traffic offences including speeding, red light running, illegal use of emergency lane and tailgating. 
Comparing gender, male is more frequent to be involved in accident. These result is supported by [9-11]. A possible explanation for this might be due to the fact that male drivers has more number of kilometres driven as compared to female drivers and number of female drivers is significantly lower than the number of male drivers. However, it is an undisputable fact that male and female have different behaviour. Sudden reactions of males to events, their nervousness as well as their desire to "prove" themselves via their driving skills create a basis for accidents [12].

In regard to the receiving summon by gender, male drivers have received more summons as compared to female drivers. This finding were supported by $[6,13,14]$ whereby number of fines and accident were greater among male drivers and higher tendency to traffic violations. It seems possible that this result is due to dangerous driving behaviour are highest in males $[15,16]$.

Furthermore, male drivers have significantly higher score in speeding, red light running, illegal use of emergency lane and tailgating among eleven traffic measures. This finding indicates that male drivers are more prone to risky driving behaviour as compared to female drivers, which in line with findings by [17]. Several studies regarding gender difference in traffic offences have shown that peer influence leads to increased speeding behaviour among male drivers [18]. One interesting finding by [19] where males and females have difference perception and preference of speeding.

Besides that, men tailgated more than women and tailgating occurred more during rushhour and when there was a traffic officer present [20]. The scenario is a norm in Malaysia as public had to travelled long distance to their workplace and the addition of registered vehicle does not seem to decreasing. Unless the service of public transportation could be improved, the possibility of publics shifting their mode of transport will increase.

With respect to the findings related to the effect of driving experience on traffic offences, high experienced driver was more prone to commit traffic offences such as speeding, red light running, dangerously cutting into traffic, using hand phone while driving/riding and driving/riding with noncompliance specification vehicle. These findings are in agreement with those obtained by $[14,21]$. It seems possible that these results are due to drivers became more sensitive to situational cues that they were likely to behave in a manner that was congruent with the surrounding situation and individuals [22]. For example, experienced drivers drove faster in clear visibility than novice drivers, yet they reduced their speed more in reduced visibility so that both groups drove at the same speed in simulated fog [8]. Even in some extent, these drivers can predict just by observing the enforcement officer whether or not they will be stopped when you violating traffic rules. This is where the role of perception of being caught (POBC) is important in enhancing traffic obligation.

Based on the findings, a special need to plan proper intervention to specific target groups and traffic violations are important in behaviour modifications and towards the reduction of national accident rate. Nevertheless, the authorities and stakeholder must have the same vision and committed in order to solved our nation's concern which in this context of road safety issues.

\section{References}

[1] World Health Organization, Global status on road report 2015, Geneva, (2015)

[2] E. Petridou, M. Moustaki, Human factors in the causation of road traffic crashes, European J. of Epidemiology, 16(9), 819-26 (2000)

[3] N.N. Sze, S.C. Wong, Diagnostic analysis of the logistic model for pedestrian injury severity in traffic crashes, Accident Analysis and Prevention, 39(6), 1267-78 (2007)

[4] R. Elvik, Why some road safety problems are more difficult to solve than others, 
Accident Analysis and Prevention, 42(4), 1089-1096 (2010)

[5] P. Bıçaksız, T. Özkan, Impulsivity and driver behaviors, offences and accident involvement: A systematic review, Transportation Research Part F: Traffic Psychology and Behaviour, 38, 194-223 (2016)

[6] B. González-iglesias, J.A. Gómez-fraguela, M.Á. Luengo-martín, Driving anger and traffic violations: Gender differences, Transportation Research Part F: Traffic Psychology and Behaviour, 15, 404-412 (2012)

[7] J. Wu, X. Yan, E. Radwan, Discrepancy analysis of driving performance of taxi drivers and non-professional drivers for red-light running violation and crash avoidance at intersections, Accident Analysis and Prevention, 91, 1-9 (2016)

[8] X. Li, X. Yan, S.C. Wong, Effects of fog, driver experience and gender on driving behavior on S-curved road segments, Accident Analysis and Prevention, 77, 91-104 (2015)

[9] E. Jiménez-Mejías, C.A. Prieto, V. Martínez-Ruiz, J.D.D.L. Del Castillo, P. LardelliClaret, J.J. Jiménez-Moleón, Gender-related differences in distances travelled, driving behaviour and traffic accidents among university students, Transportation Research Part F: Traffic Psychology and Behaviour, 27, 81-89 (2014)

[10] A.H. Al-balbissi, A.H. Al-balbissi, Role of gender in road accidents, Traffic Injury Prevention, 4(1), 64-73 (2003)

[11] M. Karacasu, A. Er, An analysis on distribution of traffic faults in accidents, based on driver's age and gender: Eskisehir case, Procedia-Social and Behavioral Sciences, 20, 776-785 (2011)

[12] Social Issues Research Center, Sex differences in driving and insurance risk, Oxford, United Kingdom, (2004)

[13] J. Rudjanakanoknad, P. Prarom, S. Panwai, Attitudes of drivers towards speed enforcement measures on Bangkok expressways, Procedia-Social and Behavioral Sciences, 48, 222-233 (2012)

[14] H.S. Lonczak, C. Neighbors, D.M. Donovan, Predicting risky and angry driving as a function of gender, Accident Analysis and Prevention, 39(3), 536-545 (2007)

[15] D. Iliescu, P. Sârbescu, The relationship of dangerous driving with traffic offenses: A study on an adapted measure of dangerous driving, Accident Analysis and Prevention, 51, 33-41 (2013)

[16] D. Yagil, Gender and age-related differences in attitudes toward traffic laws and traffic violations, Transportation Research Part F: Traffic Psychology and Behaviour, 1(2), 123-135 (1998)

[17] S. Oltedal, T. Rundmo, The effects of personality and gender on risky driving behaviour and accident involvement, Safety Science, 44(7), 621-628 (2006)

[18] M. Moller, S. Haustein, Peer influence on speeding behaviour among male drivers aged 18 and 28, Accident Analysis and Prevention, 64, 92-99 (2014)

[19] C. Horvath, I. Lewis, B. Watson, The beliefs which motivate young male and female drivers to speed: A comparison of low and high intenders, Accident Analysis and Prevention, 45, 334-341, (2012)

[20] N.M. Monteiro, S.K. Balogun, M. Kote, K. Thabano, Stationary tailgating in Gaborone, Botswana: The influence of gender, time of day, type of vehicle and presence of traffic officer, IATSS Research, 38 (2), 157-163 (2015)

[21] Y. Hoffman, T. Rosenbloom, Driving experience moderates the effect of implicit versus explicit threat priming on hazard perception test, Accident Analysis and Prevention, 92, 82-88 (2016)

[22] Y. Xu, Y. Li, L. Jiang, The effects of situational factors and impulsiveness on drivers' intentions to violate traffic rules: Difference of driving experience, Accident Analysis and Prevention, 62, 54-62 (2014) 